\title{
COMENTARIOS SOBRE LA REFORMA DEL ALQUILER EN ESPAÑA: UN BREVE ESTUDIO SOBRE EL REAL DECRETO-LEY 7/2019, SOBRE LAS FAMILIAS VULNERABLES EN ESPAÑA
}

\author{
COMENTÁRIOS SOBRE A REFORMA DO ALUGUEL EM ESPANHA: UM \\ BREVE ESTUDO SOBRE O DECRETO-LEI REAL 7/2019, SOBRE AS FAMÍLIAS \\ VULNERÁVEIS EM ESPANHA
}

COMMENTS ON THE REFORM OF RENT IN SPAIN: A BRIEF STUDY ON THE
ROYAL DECREE-LAW 7/2019, ON THE VULNERABLE FAMILIES IN SPAIN

Salvador Morales Ferrer ${ }^{1}$

\begin{abstract}
Resumen: El concepto de relación jurídica es relativamente moderno y, se introduce en la ciencia del Derecho a través de Savigny. Por otro lado, existen antecedentes en el Derecho Romano como la obligación que vincula al arrendatario con el arrendador, configurándose como un vinculum iuris. Por tanto, el legislador español el concepto arrendaticio lo ha acomodado desde el Siglo XX hasta el Siglo XXI. Como medida de protección de las familias más vulnerables tanto a las personas con discapacidad con difícil accesibilidad a la vivienda, como a las familias de bajos recursos económicos tanto nacionales como familias comunitarias o, extracomunitarias residentes legalmente en España.
\end{abstract}

Palabras Claves: Protección social; Vulnerabilidad; Personas discapacitadas; Familias falta de recursos económicos

Resumo: O conceito de relação jurídica é relativamente moderno e é introduzido na ciência do Direito através de Savigny. Por outro lado, há precedentes no Direito Romano como a obrigação que liga o inquilino ao senhorio, configurando-se como um vinculo iuris. Portanto, o legislador espanhol o conceito de aluguel acomodou do século XX ao século XXI. Como medida de proteção para as famílias mais vulneráveis, tanto para pessoas com deficiência com difícil acesso à habitação, como para famílias com baixos recursos econômicos, famílias nacionais e comunitárias, ou extra-comunidade vivendo legalmente na Espanha.

Palavras-chave: Proteção social; Vulnerabilidade; Pessoas com deficiência; Falta de recursos econômicos para as famílias

Abstract: The concept of legal relationship is relatively modern and, it is introduced in the science of Law through Savigny. On the other hand, there are precedents in Roman Law as the obligation that links the tenant with the landlord, configuring himself as a vinculum iuris. Therefore, the Spanish legislator the concept of rent has accommodated from the twentieth century to the twenty-first century. As a measure of protection for the most vulnerable families, both for people with disabilities with difficult access to housing, as well as for families with low economic resources, both national and community families, or extra-community living legally in Spain.

Keywords: Social protection; Vulnerability; Disabled people; Families lack of economic resources

1 Doctor en Derecho por el programa de Estudios Jurídicos, Ciencia Política y Criminología de la Universidad de Valencia, con la calificación Apto Cum Laude Certificado-Diploma de Estudios Avanzados TERCER CICLO - DOCTORADO por la Universidad Cardenal Herrera CEU de Valencia. Certificado de Aptitud Profesional realizado en la Escuela de Práctica Jurídica del Ilustre Colegio de abogados de Alzira. Máster Propio en Mediación y Gestión Eficiente de Conflictos por la Universidad Cardenal Herrera-Ceu (Valencia). Certificado de Aptitud Pedagógica por la Universidad de Valencia. Abogado Colegiado en el ILUSTRE COLEGIO DE ABOGADOS DE ALZIRA. Letrado Especialista para actuar en la Jurisdicción de Menores. E-mail: salvadormf@ono.com 


\section{INTRODUCCIÓN}

Como siempre es sabido desde los inicios de la humanidad siempre ha habido familias vulnerables respecto a la falta de recursos humanos o, personas discapacitadas aunque el legislador español intento promulgar varios Reales Decretos Leyes desde el siglo pasado a favor de estos grupos en relación a la vivienda y, alquiler no lo intento hasta llegado el siglo XXI, con la promulgación definitiva del Real Decreto - Ley 7/2019, de 1 de marzo de medidas urgentes en materia de vivienda y alquiler, atendiendo a la Constitución Española de 1978 y, especialmente a las normas internacionales puesto que según la doctrina entre otros los autores Luis Diez Picazo y Antonio Gullon': "La sustancia del contrato de arrendamiento radica, pues, en al cesión del uso o goce de una determinada cosa, que se enmarca en un tiempo determinado y que se obtiene a cambio de una contraprestación consistente en un precio justo", por tanto inicialmente era un simple negocio jurídico Inter partes, lo que no se aplicaba a los grupos más vulnerables en España. Con el presente artículo se pretende realizar un análisis descriptivo en los efectos jurídicos-actuales que hacen hincapié, en los inicios de Reales Decretos -Leyes desde la época franquista hasta la actualidad como elemento superior de las familias vulnerables que están en régimen de alquiler de viviendas. El artículo tiene la siguiente estructura: el primero esboza la época franquista y con que finalidad se promulgaron los Decretos de alquiler; el segundo trata del nuevo Real Decreto - Ley 7/2019, de uno de marzo de medidas urgentes en materia de vivienda y alquiler; el tercero aclara el porque se promulga el nuevo Real Decreto - Ley 7/2019, de uno de marzo de medidas urgentes en materia de vivienda y alquiler; el cuarto trata de las distintas modificaciones que realiza el nuevo Real Decreto - Ley 7/2019, de 1 de marzo de medidas urgentes en materia de vivienda y alquiler; el quinto esboza que personas son vulnerables para aplicarse la norma; el sexto aclara las modificación que realiza la norma; el séptimo trata sobre el lanzamiento de la viviendas en alquiler de las personas con vulnerabilidad; el octavo aclara la intervención de los servicios sociales para que las personas con vulnerabilidad sean protegidas; el noveno trata la protección de las personas vulnerables tanto en la Constitución española, como en la norma internacional.

\section{ANTECEDENTES HISTÓRICOS DE LA LEY DE ARRENDAMIENTOS EN ESPAÑ A}

Una de las primeras leyes de arrendamientos que marco la legislación española fue la Ley 40/1964 de 11 de junio de Reforma de Arrendamientos Urbanos ${ }^{3}$ que en su exposición de motivos señaba: "El movimiento liberador a de atemperarse no solo al ritmo de las circunstancias económicas del país, sino a las circunstancias ineludibles de la justicia social”, por lo que el legislador franquista enunciaba Justicia social, concepto vigente hoy en el sistema democrático de España. Tras la llegada de la democracia se promulgo en España el Real Decreto Ley 2/1985 de 30

2 Luis Diez Picazo y Antonio Gullon (1978). "Sistema de Derecho Civil (Vol.II) Editorial Tecnos S.A. Madrid. p. 275

3 Ley 40/1964 de 11 de junio de Reforma de Arrendamientos Urbanos. Boletín Oficial del Estado (BOE) Madrid. N. Boletín:161, p. 7654. BOE.ES- Documento BOE-A-1964-9379 (disposición derogada). 
de abril ${ }^{4}$ que en su Exposición de Motivos señalaba: "La reforma incluida en este Real Decreto Ley al aumentar la oferta reducirá la presión al alza de los alquileres con beneficio para el propietaria y para el arrendatario, lo que permitirá satisfacer las necesidades de vivienda a una generación de jóvenes que debido a la situación de bajo crecimiento económico, tiene dificultades para adquirir su vivienda, y además una mayor movilidad geográfica de los recursos humanos, lo cual va a facilitar los procesos de ajuste sectorial que todavía deben producirse en la economía española”, por lo que el legislador español necesitaba más alquileres por los nacimientos baby boom así el periódico el país ${ }^{5}$ manifiesta: "Basta echar un vistazo a la pirámide española para comprobar que éste no es el caso: las cohortes más numerosas están entre los 44 y los 64 años y están empezando a jubilarse. Son los llamados baby boomers", por tanto, los alquileres en los años 1985 estaban dirigido a estas personas que en la actualidad comprenden de estas franjas de edades y, en aquel momento tenían muchas necesidades laborales. Por otro lado, también se debe comprender la existencia de analfabetos según OEI - Sistemas Educativos Nacionales - España ${ }^{6}$ "en España Grupos de Edad Años 10 a 14 año 1981, 46.312 personas ; año 1991, 13.331 personas ; 15 a 19 años 49.066 personas año 1981 ; año 199114.066 personas ; Grupos de Edad 20 a 24 año 1981, 35.248 personas; año 1991, 14.762 personas ; 25 a 34 año 1981, 88.366 personas ; año 1991, 37.045 personas ; 35 a 44 años año 1981189.730 personas ; año 199157.571 personas; 45 a 54 años año 1981, 369.434 personas; año 1991, 132.747 personas; 55 a 64 años año 1981, 379.010 personas; año 1991, 265.878 personas; 65 y más años año 1981, 915.115 personas; año 1991, 570.039 personas", por lo que el legislador también pensó en estas personas que no sabían leer, ni escribir que tuvieran mayor movilidad geográfica y, así encontrar un trabajo laboral. Por otro lado, la Ley 29/1994 de Arrendamientos Urbanos ${ }^{7}$ en su Preámbulo 5 manifiesta: "Las disfunciones que esta situación genera el mercado son tales que han convertido el arrendamiento en una alternativa poco atractiva frente a la adquisición a la adquisición en propiedad en relación a la solución del problema de la vivienda. En este sentido, solo un 18 por 100 se encuentra aproximadamente del parque total de viviendas se encuentra en régimen de alquiler". Por lo que, en esta etapa de España la inmensa los españoles gozaban de un piso o, casa en propiedad, lo que implicaba que el legislador de esta época se intentaba promocionar el régimen de alquiler.

\section{EL NUEVO REAL DECRETO- LEY 7/2019 SOBRE LA REFORMA DE ALQUILER}

Como bien manifiesta el Real Decreto - Ley 7/2019, de 1 de marzo de medidas urgentes en materia de vivienda y alquiler ${ }^{8}$ en su exposición de motivos I manifiesta: "España afronta

4 Real Decreto- Ley 2/1985, de 30 de abril, sobre Medidas de Política Económica. Boletín Oficial del Estado (BOE) Madrid. N. Boletín:111, p. 13176. BOE.ES- Documento BOE-A-1985-8402.

5 Periódico el país "los baby boomers desestabilizan España". https:// el país.com> Economia> Negocios.p.1 6 https://www.oei.historico/quipu/espana/ESPA17.PDF.p.1

7 Ley 29/1994, de 24 de noviembre de Arrendamientos Urbanos. Boletín Oficial del Estado (BOE) Madrid. N. Boletín:282, p. 36129. https://www.boe.es7buscar/act.php?id=BOE-A-1994-26003

8 Real Decreto - Ley 7/2019, de 1 de marzo de medidas urgentes en materia de vivienda y alquiler. Boletín Oficial del Estado (BOE) Madrid. N. Boletín:55, p. 21007. BOE-ES-A-2019-3108 
retos importantes en materia de vivienda que, en la actualidad, se ligan de manera especial a la dificultad del acceso a la misma en régimen de alquiler ,además de no dar los resultados esperados en lo relativo al incremento de la oferta de vivienda y la moderación de los precios, ha situado al arrendatario de una vivienda como residencia habitual en una posición de debilidad que no responde a las condiciones mínimas de estabilidad y seguridad con las que se debe dotar al inquilino de una vivienda en posesión de justo título". Por lo que, la norma atiende más al inquilino que al propietario. Por otro lado, cabe destacar en el Real Decreto- Ley 7/2019, de 1 de marzo de medidas urgentes en materia de vivienda y alquiler ${ }^{9}$ en su exposición de motivos III párrafo tercero punto.1 manifiesta: "En este sentido, cabe recordar que el artículo 47 de la Constitución Española proclama el derecho a disfrutar de una vivienda digna y adecuada". Por lo que la doctrina entre ellos cabe mencionar al autor Loscertales ${ }^{10}$ que expresa: "a lo no tengo nada que objetar, pero se olvida que hay otro precepto (el art. 33) en la Carta Magna que reconoce el derecho a la "propiedad privada", es decir, que nadie comete ninguna infracción legal ni moral por el hecho de comprar una vivienda pagando impuestos, y luego alquilarla en el mercado libre", y en el mismo sentido cabe mencionar, el autor Perarnau"11 manifiesta: "La reforma pretende dar un giro social a los arrendamientos, ofreciendo una mayor seguridad a los inquilinos, incentivando la oferta de viviendas en alquiler a precios asequibles, incluso con estímulos fiscales, y apoyando a las familias más vulnerables, aliviando, por una parte, la carga financiera que el alquiler supone y, por otra, paliando, en lo posible, la dramática situación que el desahucio comporta". Por tanto, esta reforma legislativa esta dirigida al inquilino del arrendamiento $\mathrm{y}$, para no promover su desahucio del alquiler.

\section{PORQUE SE PROMULGA EL NUEVO REAL DECRETO-LEY 7/2019 SOBRE LA REFORMA DE ALQUILER}

Primeramente, el legislador considero los motivos siguientes: $1^{\circ}$ el poco arraigo social en España a residir en vivienda de alquiler, al haberse orientado siempre a la sociedad hacia la vivienda en propiedad; $2^{\circ}$ Escasez del parque de vivienda social ya, que la vivienda social ofrece cobertura en España a menos del 2,5\% de los hogares, una cifra que contrasta con los porcentajes sensiblemente superiores al 15\% registrados en algunos de los principales países de nuestro entorno, como Francia, Reino Unido, Suecia, Países Bajos, Austria o Dinamarca; $3^{\circ}$ El progresivo e imparable incremento del precio del alquiler ya que el precio de los alquileres se ha incrementado en los últimos tres años en más de un 15\% y, en algunas zonas, especialmente las turísticas y las grandes ciudades, el incremento duplica el registrado en el conjunto de España $; 4^{\circ}$ El elevado coste que supone el pago de una vivienda puesto que según datos de Eurostat, en el año 2017, más del 42\% de los hogares españoles destinaban más del $40 \%$ de sus ingresos al pago del alquiler. Ello supone que España se

9 Real Decreto - Ley 7/2019, de uno de marzo de medidas urgentes en materia de vivienda y alquiler. Boletín Oficial del Estado (BOE) Madrid. N. Boletín:55, p. 21007. BOE-ES-A-2019-3108

10 Loscertales Fuertes, Daniel (2019). "Guía práctica sobre la reforma del alquiler de vivienda. Real Decreto- Ley 7/2019, de 1 de marzo”. Editorial Jurídica Sepín. S.L. Las Rozas (Madrid). p.19.

11 Perarnau Moya, Joan (2019). "Los arrendamientos de viviendas tras las reformas de los Decretos -Ley 21/2018 y 7/2019 Editorial Diario La Ley 4541/2019. p. 1 
sitúa 17 puntos porcentuales por encima del valor medio de la Unión Europea; $5^{\text {a }}$ el equilibrio de la posición jurídica del propietario y el inquilino en la relación arrendaticia, tanto a nivel contractual como también en materia procesal; $6^{\circ}$ Facultar la trasparencia informática del consumidor. Por tanto, esta fueron las causas de la necesidad de la sociedad española.

\section{LAS MODIFICACIONES QUE CONLLEVA EL NUEVO REAL DECRETO- LEY 7/2019 SOBRE LA REFORMA DE ALQUILER SOBRE LAS FAMILIAS MÁS VULNERABLES}

El título III realiza una incorporación una modificación del procedimiento de desahucio de vivienda cuando afecte a los hogares vulnerables estableciendo que la determinación de la situación de vulnerabilidad producirá la suspensión del procedimiento hasta que se adopten las medidas que los servicios sociales estimen oportunas por un plazo máximo de un mes, o de tres meses cuando el demandante sea persona jurídica. De esta forma se clarifica el procedimiento, introduciendo mayor seguridad jurídica y medidas específicas para atender a aquellas situaciones que demanden una mayor protección social. Por lo que el problema es que sigue sin definirse que se entiende por hogares vulnerables y que se atribuye a unos servicios sociales indeterminados, la capacidad de apreciar los indicios de la existencia de dicha situación. Por tanto, se inició la Proposición de Ley de emergencia habitacional en familias vulnerables en el ámbito habitacional y de la pobreza energética presentada en el Congreso de los Diputados el día 30 de enero de 2018. En ese documento se define el hogar vulnerable como las viviendas donde viven personas o familias que se encuentran en exclusión residencial, independientemente de tener título legal habilitante; y la exclusión residencial, es como aquella situación en la que las personas o familias tienen ingresos netos inferiores a 2,5 veces el iprem cuando se trate de personas que vivan solas, o ingresos netos inferiores a 3 veces el iprem cuando se trate de unidades de convivencia, o ingresos inferiores a 3,5 veces el iprem cuando se trate de personas con discapacidad o gran dependencia. Por otro lado, la lectura de la Proposición de ley y de su Exposición de Motivos que modificó la Ley 1/2000, de 7 de enero, de Enjuiciamiento Civil en materia de vivienda y alquiler. ${ }^{12}$ permite verificar la existencia de una sistemática y un contenido parecido a la del parte expositiva que señalaba:

\footnotetext{
Por su parte, el título III incorpora una modificación del procedimiento de desahucio de vivienda cuando afecte a hogares vulnerables, estableciendo que la determinación de la situación de vulnerabilidad producirá la suspensión del procedimiento hasta que se adopten las medidas que los servicios sociales estimen oportunas por un plazo máximo de un mes, o de dos meses cuando el demandante sea persona jurídica.
}

De esta forma, se clarifica el procedimiento, introduciendo mayor seguridad jurídica y medidas específicas para atender a aquellas situaciones que demanden una mayor protección social. Según el artículo tercero de la Modificación de la Ley 1/2000, de 7 de enero, de Enjuiciamiento Civil señala: " 1 ter. En el requerimiento de pago al demandado, se informará al mismo de la posibilidad de que

12 Ley $1 / 2000$, de 7 de enero, de Enjuiciamiento Civil en materia de vivienda y alquiler Boletín Oficial del Estado (BOE) Jefatura del Estado Madrid. N. Boletín:340 p.12. http://www.boe.es/buscar/act?php id=BOE-A-2018-17293 
acuda a los servicios sociales, y en su caso, de la posibilidad de autorizar la cesión de sus datos a estos, a efectos de que puedan apreciar la posible situación de vulnerabilidad. En caso de que la Administración competente apreciase indicios de la existencia de dicha situación, se notificará al órgano judicial inmediatamente. Recibida dicha comunicación, el Letrado de la Administración de Justicia suspenderá el proceso hasta que se adopten las medidas que los servicios sociales estimen oportunas, durante un plazo máximo de suspensión de un mes a contar desde la recepción de la comunicación de los Servicios Sociales al órgano judicial, o de dos meses si el demandante es una persona jurídica. Una vez adoptadas las medidas o transcurrido el plazo se alzará la suspensión y continuará el procedimiento por sus trámites. En estos supuestos, la cédula de emplazamiento al demandado habrá de contener datos de identificación de los Servicios Sociales a los que puede acudir el ciudadano." Por otro lado, fue mas conciso el Real Decreto ley 21/2018, de 14 de diciembre, de medidas urgentes en materia de vivienda y alquiler ${ }^{13}$ así cabe mencionar su Exposición de Motivos II señalaba: "Por su parte, el título III incorpora una modificación del procedimiento de desahucio de vivienda cuando afecte a hogares vulnerables, estableciendo que la determinación de la situación de vulnerabilidad producirá la suspensión del procedimiento hasta que se adopten las medidas que los servicios sociales estimen oportunas por un plazo máximo de un mes, o de dos meses cuando el demandante sea persona jurídica. De esta forma se clarifica el procedimiento, introduciendo mayor seguridad jurídica y medidas específicas para atender a aquellas situaciones que demanden una mayor protección social". Po, lo que, da más seguridad jurídica a las familias más vulnerables.

\section{5. ¿QUÉ PERSONAS OFRECEN MAYOR VULNERABILIDAD?}

Primeramente hay que concretar estos elementos de las familiar vulnerables la especial vulnerabilidad que viven muchas familias y hogares después de años de profunda crisis económica caracterizada por una intensa destrucción y precarización del empleo, pues esto afecta a los españoles, los ciudadanos comunitarios y residentes extracomunitarios en España puesto que la sociedad en España ha crecido por es tas dos segundas causas, lo que conlleva es el desahucio de alquiler de estas familias vulnerables Por otro lado, la necesidad de accesibilidad a las vivienda de las personas con discapacidad o, movilidad reducida, por lo que provoca la dificultad de acceso en un contexto demográfico marcado por un progresivo y alarmante envejecimiento de la población: Se prevé que, en la próxima década, la población mayor de 65 años superará sobradamente los 10 millones de personas, al hilo cabe mencionar como ejemplo la Sentencia de la Audiencia Provincial de Lleida ${ }^{14}$ que señala en sus Fundamentos de Derecho Tercero.1: "Reproduce además en esta alzada las alegaciones efectuadas en primera instancia, relativas a que se encuentra en una situación de estado de necesidad y especial vulnerabilidad, dado que tiene una hija menor de edad y no dispone de ingresos suficientes para hacerse cargo de todos los gastos del día a día,

13 Real Decreto ley 21/2018, de 14 de diciembre, de medidas urgentes en materia de vivienda y alquiler. Boletín Oficial del Estado (BOE) Jefatura del Estado Madrid. N. Boletín:304, p.6. BOE.ES- Documento BOE-A-1964-9379 (disposición derogada). http://www.boe.es $>$ buscar

14 Sentencia de la Audiencia Provincial de Lleida (Sección 2a) (Ponente IIlmo. Sr. D María del Carmen Bernat Álvarez) (Sentencia nº157/2019 de 28 de marzo) JUR 2019/142886.Aramzadi 
extremo que quedó debidamente acreditado con la documentación aportada al escrito de oposición a la demanda. Refiere que su situación personal y familiar impide que pueda acceder a una vivienda digna para cubrir las necesidades de la menor, por lo que está en trámite para acceder a un alquiler social sobre el mismo inmueble objeto de autos, estando a la espera de la resolución del organismo público, siendo que si se procede al desalojo y después se concede el alquiler social del inmueble, el perjuicio que se causaría sería más grave que el hecho de suspender el plazo para acordar y proceder al lanzamiento; cuestiones que han sido convenientemente resueltas por la juzgadora". Este sentido, actuarán los servicios sociales para que en la misma vivienda habitual en régimen de alquiler que no puedan pagar no sea desahuciada la familia. Por último, cabe mencionar el Real Decreto-ley 5/2017, de 17 de marzo, por el que se modifica el Real Decreto-ley 6/2012, de 9 de marzo, de medidas urgentes de protección de deudores hipotecarios sin recursos, y la Ley $1 / 2013$, de 14 de mayo, de medidas para reforzar la protección a los deudores hipotecarios, reestructuración de deuda y alquiler social ${ }^{15}$ que en su artículo $1^{\circ}$. Uno B menciona las familias de espacial vulnerabilidad: "Asimismo, se entiende que se encuentran en una circunstancia familiar de especial vulnerabilidad: $10^{\circ}$ La familia numerosa, de conformidad con la legislación vigente. 2. ${ }^{\circ}$ La unidad familiar monoparental con hijos a cargo. $3 .^{\circ}$ La unidad familiar de la que forme parte un menor de edad. $4 .^{\circ}$ La unidad familiar en la que alguno de sus miembros tenga declarada discapacidad superior al 33 por ciento, situación de dependencia o enfermedad que le incapacite acreditadamente de forma permanente, para realizar una actividad laboral. 5. ${ }^{\circ}$ La unidad familiar con la que convivan, en la misma vivienda, una o más personas que estén unidas con el titular de la hipoteca o su cónyuge por vínculo de parentesco hasta el tercer grado de consanguinidad o afinidad, y que se encuentren en situación personal de discapacidad, dependencia, enfermedad grave que les incapacite acreditadamente de forma temporal o permanente para realizar una actividad laboral. $6{ }^{\circ}$ La unidad familiar en que exista una víctima de violencia de género. 7. ${ }^{\circ}$ El deudor mayor de 60 años, aunque no reúna los requisitos para ser considerado unidad familiar según lo previsto en la letra a) de este número". Por lo que, en si la norma reconocía las familias con especial vulnerabilidad y como se tenía que aplicar la normativa del alquiler de viviendas urbanas.

\section{LA MODIFICACIÓN DEL REAL DECRETO- LEY 7/2019 SOBRE LA REFORMA DE ALQUILER EN LAS PERSONAS DE VULNERABLE SITUACIÓN}

Primeramente, se debe contemplar que el del Real Decreto- Ley 1 de marzo de medidas urgentes en materia de vivienda y alquiler ${ }^{16}$ modifica el artículo siguiente de la Ley de Enjuiciamiento

15 Real Decreto-ley 5/2017, de 17 de marzo, por el que se modifica el Real Decreto-ley 6/2012, de 9 de marzo, de medidas urgentes de protección de deudores hipotecarios sin recursos, y la Ley 1/2013, de 14 de mayo, de medidas para reforzar la protección a los deudores hipotecarios, reestructuración de deuda y alquiler social. Boletín Oficial del Estado (BOE) Jefatura del Estado Madrid. N. Boletín:66, p.19788. http:// www.boe.es $>$ BOE $>$ Calendario $>18 / 3 / 2017$

16 Real Decreto - Ley 7/2019, de 1 de marzo de medidas urgentes en materia de vivienda y alquiler. Boletín Oficial del Estado (BOE) Madrid. N. Boletín:55, p.21020. BOE-ES-A-2019-3108 
Civil Español (LEC) 441 señala: "se informará al demandando de la posibilidad de que acuda a los servicios sociales, y en su caso, de la posibilidad de autorizar la cesión de sus datos a estos, a efectos de que puedan apreciar la posible situación de vulnerabilidad. A los mismos efectos, se comunicará, de oficio por el Juzgado, la existencia del procedimiento a los servicios sociales. En caso de que los servicios sociales confirmasen que el hogar afectado se encuentra en situación de vulnerabilidad social y/o económica, se notificará al órgano judicial inmediatamente. Recibida dicha comunicación, el Letrado de la Administración de Justicia suspenderá el proceso hasta que se adopten las medidas que los servicios sociales estimen oportunas, durante un plazo máximo de suspensión de un mes a contar desde la recepción de la comunicación de los servicios sociales al órgano judicial, o de tres meses si el demandante es una persona jurídica. Una vez adoptadas las medidas o transcurrido el plazo se alzará la suspensión y continuará el procedimiento por sus trámites. En estos supuestos, la cédula de emplazamiento al demandado habrá de contener datos de identificación de los servicios sociales a los que puede acudir el ciudadano". Por lo que, tendrá que acudir el ciudadano a los servicios sociales para que se paralice el desahucio siempre presentando los documentos fehacientes como que no tiene posibilidades de pagar el alquiler, al mismo tiempo también se modifica el artículo siguiente de la Ley de Enjuiciamiento Civil Español (LEC) 594 que señalaba: "El plazo de espera legal al que se refiere el artículo anterior no será de aplicación en la ejecución de resoluciones de condena de desahucio por falta de pago de rentas o cantidades debidas, o por expiración legal o contractual del plazo, que se regirá por lo previsto en tales casos. No obstante, cuando se trate de vivienda habitual, con carácter previo al lanzamiento", por lo que como enuncia la Ley de Enjuiciamiento Civil Español (LEC) aunque existan otros lanzamientos de desahucio siempre tiene que comprender la vivienda habitual, por lo que el legislador español ampara a las familias de vulnerable situación

\section{EL LANZAMIENTOY LA INTERVENCIÓN DE LOS SERVICIOS SOCIALES EN EL REAL DECRETO- LEY 7/2019 SOBRE LA REFORMA DE ALQUILER EN LAS PERSONAS DE VULNERABLE SITUACIÓN}

Por lo que, en el nuevo Decreto Ley 7/2019 sobre la reforma de alquiler en personas de vulnerable situación en el artículo 440 en sus apartados 3 y 4 de la Ley de Enjuiciamiento Civil Española (LEC) ${ }^{17}$ quedan redactados en los siguientes términos: "3. En los casos de demandas sentencia fuese condenatoria y no se recurriera, se procederá al lanzamiento en el día y la hora fijadas, sin necesidad de notificación posterior el requerimiento expresará el día y la hora que se hubieran señalado para que tengan lugar la eventual vista en caso de oposición del demandando, para la que servirá de citación, y el día y la hora exactos para la práctica del lanzamiento en caso de que no hubiera oposición. Asimismo, se expresará que en caso de solicitar asistencia jurídica gratuita el demandado, deberá hacerlo en los tres días siguientes a la práctica del requerimiento, así como que la falta de oposición al requerimiento supondrá la prestación de su consentimiento a la resolución del contrato de arrendamiento que le vincula con el arrendador. El requerimiento se

17 Real Decreto - Ley 7/2019, de 1 de marzo de medidas urgentes en materia de vivienda y alquiler. Boletín Oficial del Estado (BOE) Madrid. N. Boletín:55, pps.21019-21020. BOE-ES-A-2019. 
practicará en la forma prevista en el artículo 161 de esta Ley, teniendo en cuenta las previsiones contenidas en apartado 3 del artículo 155 y en el último párrafo del artículo 164, apercibiendo al demandado de que, de no realizar ninguna de las actuaciones citadas, se procederá a su inmediato lanzamiento, sin necesidad de notificación posterior, así como de los demás extremos comprendidos en el apartado siguiente de este mismo artículo. Si el demandado no atendiere el requerimiento de pago o no compareciere para oponerse o allanarse, el Letrado de la Administración de Justicia dictará decreto dando por terminado el juicio de desahucio y se procederá el lanzamiento en el día y la hora fijadas. Si el demandado atendiere el requerimiento en cuanto al desalojo del inmueble sin formular oposición ni pagar la cantidad que se reclamase, el Letrado de la Administración de Justicia lo hará constar, y dictará decreto dando por terminado el procedimiento, y dejando sin efecto la diligencia de lanzamiento, a no ser que el demandante interese su mantenimiento para que se levante acta sobre el estado en que se encuentre la finca, dando traslado al demandante para que inste el despacho de ejecución en cuanto a la cantidad reclamada, bastando para ello con la mera solicitud. En los dos supuestos anteriores, el decreto dando por terminado el juicio de desahucio, impondrá las costas al demandado e incluirá las rentas debidas que se devenguen con posterioridad a la presentación de la demanda hasta la entrega de la posesión efectiva de la finca, tomándose como base de la liquidación de las rentas futuras, el importe de la última mensualidad reclamada al presentar la demanda. Si el demandado formulara oposición, se celebrará la vista en la fecha señalada. 4. En todos los casos de desahucio, también se apercibirá al demandado en el requerimiento que se le realice que, de no comparecer a la vista, se declarará el desahucio sin más trámites y que queda citado para recibir la notificación de la sentencia que se dicte el sexto día siguiente al señalado para la vista. Igualmente, en la resolución que se dicte teniendo por opuesto al demandado se fijará día y horas exactas para que tenga lugar, en su caso, el lanzamiento, que deberá verificarse antes de treinta días desde la fecha señalada para la vista, advirtiendo al demandado que, si la sentencia fuese condenatoria y no se recurriera, se procederá al lanzamiento en el día y la hora fijadas, sin necesidad de notificación posterior", por lo que en la redacción del Real Decreto- Ley 7/2019 sobre la reforma de alquiler en las personas de vulnerable manifiesta el día y la hora exacta que se hubiera fijado respecto al lanzamiento. Por tanto, el decreto de admisión de juicio de desahucio por falta de pago de pagos o rentas de alquiler debidas, se segura la fecha real, por lo que se requerirá de cada partido judicial, sino también de la práctica y trascurso del plazo de diez días a las familias que ostentan el alquiler. Por lo cual, el nuevo Decreto Ley 7/2019 sobre la reforma de alquiler en personas de vulnerable situación en el artículo 440 en sus apartados 3 y 4 de la Ley de Enjuiciamiento Civil Española (LEC) ${ }^{18}$ señala: "Dos. Se modifican los apartados 3 y 4 del artículo 440, que quedan redactados en los siguientes términos: “3. En los casos de demandas en las que se ejercite la pretensión de desahucio por falta de pago de rentas o cantidades debidas, acumulando o no la pretensión de condena al pago de las mismas, el Letrado de la Administración de Justicia, tras la admisión, y previamente a la vista que se señale, requerirá al demandado para que, en el plazo de diez días, desaloje el inmueble, pague al actor o, en caso de pretender la enervación, pague la totalidad de lo que deba o ponga a disposición de aquel en el tribunal o notarialmente el importe de

18 Real Decreto - Ley 7/2019, de 1 de marzo de medidas urgentes en materia de vivienda y alquiler. Boletín Oficial del Estado (BOE) Madrid. N. Boletín:55, pps.21019-21020. BOE-ES-A-2019-3108 
las cantidades reclamadas en la demanda y el de las que adeude en el momento de dicho pago enervador del desahucio; o en otro caso comparezca ante éste y alegue sucintamente, formulando oposición, las razones por las que, a su entender, no debe, en todo o en parte, la cantidad reclamada o las circunstancias relativas a la procedencia de la enervación. Si el demandante ha expresado en su demanda que asume el compromiso a que se refiere el apartado 3 del artículo 437, se le pondrá de manifiesto en el requerimiento, y la aceptación de este compromiso equivaldrá a un allanamiento con los efectos del artículo 21. Además, el requerimiento expresará el día y la hora que se hubieran señalado para que tengan lugar la eventual vista en caso de oposición del demandando, para la que servirá de citación, y el día y la hora exactos para la práctica del lanzamiento en caso de que no hubiera oposición. Asimismo, se expresará que en caso de solicitar asistencia jurídica gratuita el demandado, deberá hacerlo en los tres días siguientes a la práctica del requerimiento, así como que la falta de oposición al requerimiento supondrá la prestación de su consentimiento a la resolución del contrato de arrendamiento que le vincula con el arrendador. El requerimiento se practicará en la forma prevista en el artículo 161 de esta Ley, teniendo en cuenta las previsiones contenidas en apartado 3 del artículo 155 y en el último párrafo del artículo 164, apercibiendo al demandado de que, de no realizar ninguna de las actuaciones citadas, se procederá a su inmediato lanzamiento, sin necesidad de notificación posterior, así como de los demás extremos comprendidos en el apartado siguiente de este mismo artículo. Si el demandado no atendiere el requerimiento de pago o no compareciere para oponerse o allanarse, el Letrado de la Administración de Justicia dictará decreto dando por terminado el juicio de desahucio y se procederá el lanzamiento en el día y la hora fijadas. Si el demandado atendiere el requerimiento en cuanto al desalojo del inmueble sin formular oposición ni pagar la cantidad que se reclamase, el Letrado de la Administración de Justicia lo hará constar, y dictará decreto dando por terminado el procedimiento, y dejando sin efecto la diligencia de lanzamiento, a no ser que el demandante interese su mantenimiento para que se levante acta sobre el estado en que se encuentre la finca, dando traslado al demandante para que inste el despacho de ejecución en cuanto a la cantidad reclamada, bastando para ello con la mera solicitud. En los dos supuestos anteriores, el decreto dando por terminado el juicio de desahucio, impondrá las costas al demandado e incluirá las rentas debidas que se devenguen con posterioridad a la presentación de la demanda hasta la entrega de la posesión efectiva de la finca, tomándose como base de la liquidación de las rentas futuras, el importe de la última mensualidad reclamada al presentar la demanda. Si el demandado formulara oposición, se celebrará la vista en la fecha señalada. 4. En todos los casos de desahucio, también se apercibirá al demandado en el requerimiento que se le realice que, de no comparecer a la vista, se declarará el desahucio sin más trámites y que queda citado para recibir la notificación de la sentencia que se dicte el sexto día siguiente al señalado para la vista. Igualmente, en la resolución que se dicte teniendo por opuesto al demandado se fijará día y horas exactas para que tenga lugar, en su caso, el lanzamiento, que deberá verificarse antes de treinta días desde la fecha señalada para la vista, advirtiendo al demandado que, si la sentencia fuese condenatoria y no se recurriera, se procederá al lanzamiento en el día y la hora fijadas, sin necesidad de notificación posterior" y, en el artículo $549.4^{019}$ señala: "No obstante, cuando se trate de vivienda habitual", por

19 Real Decreto - Ley 7/2019, de 1 de marzo de medidas urgentes en materia de vivienda y alquiler. Boletín Oficial del Estado (BOE) Madrid. N. Boletín:55, p. 21020. BOE-ES-A-2019-3108 
lo que el legislador español siempre ésta pensando en todas las personas que viven en régimen de alquiler en la la vivienda.

\section{LA INTERVENCIÓN DE LOS SERVICIOS SOCIALES EN EL RÉGIMEN DE ALQUILER DE LAS FAMILIAS VULNERABLES}

En este contexto, cabe mencionar el nuevo Decreto Ley 7/2019, de 1 de marzo de medidas urgentes en materia de vivienda y alquiler que introduce en la Ley de Enjuiciamiento Civil Española (LEC) en su punto 5 un nuevo apartado que señala: "se informará al demandando de la posibilidad de que acuda a los servicios sociales, y en su caso, de la posibilidad de autorizar la cesión de sus datos a estos, a efectos de que puedan apreciar la posible situación de vulnerabilidad. A los mismos efectos, se comunicará, de oficio por el Juzgado, la existencia del procedimiento a los servicios sociales. En caso de que los servicios sociales confirmasen que el hogar afectado se encuentra en situación de vulnerabilidad social y/o económica, se notificará al órgano judicial inmediatamente. Recibida dicha comunicación, el Letrado de la Administración de Justicia suspenderá el proceso hasta que se adopten las medidas que los servicios sociales estimen oportunas, durante un plazo máximo de suspensión de un mes a contar desde la recepción de la comunicación de los servicios sociales al órgano judicial, o de tres meses si el demandante es una persona jurídica. Una vez adoptadas las medidas o transcurrido el plazo se alzará la suspensión y continuará el procedimiento por sus trámites. En estos supuestos, la cédula de emplazamiento al demandado habrá de contener datos de identificación de los servicios sociales a los que puede acudir el ciudadano". Por lo que, el nuevo Real Decreto es muy flexible indicando que el juzgado informará a los servicios sociales de los problemas de índole económico que sufren las familias vulnerables ya sean discapacitados, familias españolas, extranjeros comunitarios o, residentes extranjeros extracomunitarios residentes legalmente en España.

\section{LA PROTECCIÓN DE LAS FAMILIAS VULNERABLES EN LA CONSTI- TUCIÓN ESPAÑOLA Y EN LA DECLARACIÓN UNIVERSAL DE LOS DERE- CHOS HUMANOS}

El nuevo Decreto Ley 7/2019 sobre la reforma de alquiler ${ }^{20}$ en su Exposición de Motivos I párrafo $3^{\circ}$ señala: "En este sentido, cabe recordar que el artículo $47^{21}$ de la Constitución Española proclama el derecho a disfrutar de una vivienda digna y adecuada", en este sentido cabe citar a la doctrina entre ellos al autor Loscertales ${ }^{22}$ que manifiesta: "a lo que nada tengo que objetar, pero

20 Real Decreto - Ley 7/2019, de 1 de marzo de medidas urgentes en materia de vivienda y alquiler. Boletín Oficial del Estado (BOE) Madrid. N. Boletín:55, p. 21007. BOE-ES-A-2019-3108

21 Constitución Española (2003). Edición Especial Editorial Aranzadi S.A. (Navarra) p. 97. en su artículo 47 señala: "Todos los españoles tienen derecho a disfrutar de una vivienda digna y adecuada. Los poderes públicos promoverán las condiciones necesarias y establecerán las normas pertinentes para hacer efectivo este derecho, regulando la utilización del suelo de acuerdo con el interés general “

22 Loscertales Fuertes, Daniel (2019). "Guía práctica sobre la reforma del alquiler de vivienda. Real Decreto- Ley 7/2019, de 1 de marzo” Op. Cit, p. 19. 
si se olvida que hay otro precepto (el art. 33) en la Carta Magna que reconoce el derecho a la propiedad privada" así el artículo 33 de la Constitución Española de $1978^{23}$ señala: "Se reconoce el derecho a la propiedad privada", por tanto la nueva normativa que promulgo el legislador español está hecha para las familiar vulnerables, como lo he seguido afirmando.

VIII.I El nuevo el Real Decreto- Ley 7/2019 sobre la reforma de alquiler en el ámbito internacional

Como bien menciona el Real Decreto-ley 7/2019, de 1 de marzo, de medidas urgentes en materia de vivienda y alquiler ${ }^{24}$ en su Exposición de Motivos I párrafo tercero señala: "a nivel internacional, la Declaración Universal de Derechos Humanos de Naciones Unidas en su artículo 25 sitúa la vivienda como objeto de un derecho fundamental de las personas", por lo que el legislador se remite a este artículo 25. $1^{\text {o25 }}$ que literalmente señala:" Toda persona tiene derecho a un nivel de vida adecuado que le asegure, así como a su familia, la salud y el bienestar, y en especial la alimentación, el vestido, la vivienda", por se atiende a los Derechos Humanos de las personas con especial protección las viviendas en régimen de alquiler y con vulnerabilidad familiar. Por último, cabe mencionar la Sentencia del Tribunal Supremo ${ }^{26}$ que señala en sus Fundamentos Jurídicos Segundo: "entre los que se encuentran los que sirven de soporte a un mero derecho procesal cuya finalidad sea la de poseer la cosa para disfrutarla o para usarla, legitimando por tanto al arrendatario frente al poseedor sin título". Por lo que afianza más al legislador español en promulgar este Real Decreto-ley 7/2019, de 1 de marzo, de medidas urgentes en materia de vivienda y alquiler ${ }^{27}$, como elemento de apoyo para las familias vulnerables.

\section{CONCLUSIONES}

$1^{\mathrm{o}}$ El Contrato de arrendamiento siempre ha sido un contrato inter partes, donde solo se observó una finalidad económica.

$2^{\circ}$ En los inicios de la época franquista el legislador intento acomodar la Ley de arrendamientos a ala Justica Social, lo que implica a la clase obrera, para desenvolverse socialmente.

$3^{\circ}$ A partir de 1985 ya entrada la democracia el legislador español legislo de acuerdo a la natalidad de los baby boomers, lo que implico que ciertos grupos sociales españoles entre los grupos de analfabetos y no analfabetos que pudieran desplazarse por falta de recursos económicos en todo el territorio nacional, para encontrar un puesto de trabajo.

23 Constitución Española (2003). Op. Cit., p. 92

24 Real Decreto - Ley 7/2019, de 1 de marzo de medidas urgentes en materia de vivienda y alquiler. Boletín Oficial del Estado (BOE) Madrid. N. Boletín:55, p. 21007. BOE-ES-A-2019-3108

25 Declaración Internacional de Derechos Humanos. Adoptada y proclamada por la Asamblea General en su resolución 217 A (III), de 10 de diciembre de 1948.p. 9 htpp: //www.un.org/es/universal-declarationhuman-rights

26 Sentencia del Tribunal Supremo (Sala Primera, de lo civil) (Ponente Malpica González-Elipe,Matías) (Sentencia 31 de Enero 1995) Rec.2806/1991. La Ley.

27 Real Decreto - Ley 7/2019, de 1 de marzo de medidas urgentes en materia de vivienda y alquiler. Boletín Oficial del Estado (BOE) Madrid. N. Boletín:55, p. 21007. BOE-ES-A-2019-3108 
$4^{\circ}$ Entrado el Siglo XXI, el legislador español se encuentra con ciertos grupos sociales que hay que proteger como las personas discapacitadas para mejor accesibilidad a la vivienda, familias sin recursos económicos tanto nacionales como como comunitarios,o, residentes extracomunitarios que residen legalmente en España.

$5^{\circ}$ Aunque la Constitución Española de 1978 contemplaba una vivienda digna no se aplicó hasta la promulgación del Real Decreto - Ley 7/2019, de 1 de marzo de medidas urgentes en materia de vivienda y alquiler en España.

$6^{\circ}$ Por tanto es un avance social para las familias con carencias económicas tengan una vivienda digna en régimen de alquiler como lo propugna tanto la Constitución Española de 1978 y, la Declaración de Derechos Humanos.

\section{BIBLIOGRAFÍA}

\subsection{Autores}

Los certales Fuertes, Daniel (2019). Guía práctica sobre la reforma del alquiler de vivienda. Real DecretoLey 7/2019, de 1 de marzo. Editorial Jurídica Sepín. S.L. Las Rozas (Madrid)

Luis Diez Picazo y Antonio Gullon (1978). Sistema de Derecho Civil (Vol.II) Editorial Tecnos S.A. Madrid. Perarnau Moya, Joan (2019). Los arrendamientos de viviendas tras las reformas de los Decretos -Ley 21/2018 y 7/2019 Editorial Diario La Ley 4541/2019.

\subsection{Códigos}

Constitución Española (2003). Edición Especial Editorial Aranzadi S.A. (Navarra).

\subsection{Legislación}

Ley 40/1964 de 11 de junio de Reforma de Arrendamientos Urbanos. Boletín Oficial del Estado (BOE) Madrid. N. Boletín:161, p.7654. BOE.ES- Documento BOE-A-1964-9379 (disposición derogada).

Real Decreto- Ley 2/1985, de 30 de abril, sobre Medidas de Política Económica. Boletín Oficial del Estado (BOE) Madrid. N. Boletín:111, p.13176. BOE.ES- Documento BOE-A-1985-8402

Ley 29/1994, de 24 de noviembre de Arrendamientos Urbanos. Boletín Oficial del Estado (BOE) Madrid. N. Boletín:282, p.36129. https://www.boe.es7buscar/act.php?id=BOE-A-1994-26003

Ley 1/2000, de 7 de enero, de Enjuiciamiento Civil en materia de vivienda y alquiler Boletín Oficial del Estado (BOE) Jefatura del Estado Madrid. N. Boletín:340 p. 12. http://www.boe.es/buscar/act?php $\underline{\mathrm{id}=\mathrm{BOE}-\mathrm{A}-2018-17293}$

Real Decreto-ley 5/2017, de 17 de marzo, por el que se modifica el Real Decreto-ley 6/2012, de 9 de marzo, de medidas urgentes de protección de deudores hipotecarios sin recursos, y la Ley 1/2013, de 14 de mayo, de medidas para reforzar la protección a los deudores hipotecarios, reestructuración de deuda y alquiler social. Boletín Oficial del Estado (BOE) Jefatura del Estado Madrid. N. Boletín:66, p. 19788. http://www. boe.es $>$ BOE $>$ Calendario 18/3/2017.

Real Decreto ley 21/2018, de 14 de diciembre, de medidas urgentes en materia de vivienda y alquiler. Boletín Oficial del Estado (BOE) Jefatura del Estado Madrid. N. Boletín:304, p. 6. BOE.ES- Documento BOE-A-1964-9379 (disposición derogada). http://www.boe.es buscar

Real Decreto - Ley 7/2019, de 1 de marzo de medidas urgentes en materia de vivienda y alquiler. Boletín Oficial del Estado (BOE) Madrid. N. Boletín:55, p. 21007. BOE-ES-A-2019-3108 


\subsection{Legislación Internacional}

Declaración Internacional de Derechos Humanos. Adoptada y proclamada por la Asamblea General en su resolución 217 A (III), de 10 de diciembre de 1948. p. 9 htpp: //www.un.org/es/universal-declaration-human-rights

\subsection{Jurisprudencia}

Sentencia del Tribunal Supremo (Sala Primera, de lo civil) (Ponente Malpica González-Elipe, Matías) (Sentencia 31 de Enero 1995) Rec.2806/1991. La Ley.

Sentencia de la Audiencia Provincial de Lleida (Sección 2 ${ }^{a}$ ) (Ponente IIlmo. Sr. D María del Carmen Bernat Álvarez) (Sentencia nº157/2019 de 28 de marzo) JUR 2019/142886.Aramzadi.

1.6. Periódico y otras informaciones

Periódico el país "los baby boomers desestabilizan España”. https:// el país.com> Economia > Negocios. https://www.oei.historico/quipu/espana/ESPA17.PDF

Data de submissão do artigo: Agosto de 2019

Data de aceite do artigo: Março de 2020(*)

\section{(*) NOTA TÉCNICA:}

Esclarecemos que, em razão do ataque de hackers a que foi submetido o conjunto de periódicos da Universidade Federal de Goiás (UFG), ao que se inclui a Revista da Faculdade de Direito da UFG (RFD/UFG), os artigos ordenados entre os números 21-30, referentes ao volume 43 , embora tenham sido recebidos e aceitos em datas distintas e anteriores, dado o perecimento de suas referências, foram todos registrados com o expediente de aceite no mês de março de 2020 . 